\title{
Microstructural and Mechanical Effects of Thermo-Mechanical Processing on ATI 718Plus $\AA$ Contoured Rings
}

Octavio Covarrubias

Frisa Aerospace SA de CV, Valentín G Rivero 200, Col. Los Treviño, Santa Catarina NL, 66150

México

ocovarrubias@frisa.com

\section{Key words: 718 Plus $®$, forging, heat-treatment}

\begin{abstract}
ATI 718Plus ${ }^{\circledR}$ is a nickel-base superalloy designed to promote resistance and thermal stability at elevated temperatures. Beside these properties, this material presents superior formability during forging operations, making ATI 718Plus ${ }^{\circledR}$ a suitable material for the manufacture of non-rotating and rotating components for jet engine and land-based turbines. Present contribution summarizes main results when several contoured rings were produced by ringrolling processes considering selected parameters as temperature and deformation ratio. Effect of solution and precipitation heat treatments on ATI 718Plus ${ }^{\circledR}$ microstructure and mechanical properties are also reported. These results include tensile testing at elevated temperature and stressrupture testing. Microstructural evaluations performed by optical microscopy and electronic microscopy, complement reported results.
\end{abstract}

\section{Introduction}

Superalloy ATI 718Plus ${ }^{\circledR}$ is an alternative material for the design and construction of components to be used in jet-engines and land-based turbines for energy generation. ATI 718Plus ${ }^{\circledR}$ is a precipitation hardened nickel-base alloy designed to have a better thermal stability than 718 alloy and excellent processing characteristics at hot-working temperatures [1]. Other advantage of ATI 718 Plus ${ }^{\circledR}$ alloy is a lower cost due to lower intrinsic raw materials cost $[2,3]$.

Ring-rolling procedures are optimal option for the manufacture of seamless rings, having important benefits as increase of material resistance and reduction of input weight. Use of contoured shapes simplifies and improves manufacturing processes by reduction of machining touch times and in some cases, elimination of welding operations. [4].

Microstructure of ATI 718Plus ${ }^{\circledR}$ alloy can be described as a matrix of austenitic grains (gamma) in which precipitation of $\mathrm{Ni}_{3}(\mathrm{Al}, \mathrm{Ti})$ gamma-prime is promoted to develop desired properties. Other precipitates, as $\mathrm{Ni}_{3}(\mathrm{Nb})$ delta-phase can be present at grain boundaries. Since extensive research is oriented to evaluate and characterize 718 Plus ${ }^{\circledR}$ metallurgy $[4,5,6,7]$, present contribution describes microstructural and mechanical characteristics when contoured rings of ATI 718Plus ${ }^{\circledR}$ are processed by ring-rolling procedures and exposed to selected heat treatment conditions.

\section{Experimentation}

A VIM+VAR $203.0 \mathrm{~mm}$ diameter billet was selected to extract several increments for the production of contoured rings with a weight of $80.0 \mathrm{~kg}$ and dimensions: $560.0 \mathrm{~mm}$ outer diameter, $455.0 \mathrm{~mm}$ internal diameter and $150.0 \mathrm{~mm}$ height. Table I summarizes the chemical composition of the starting material. 
Table I: Chemical Composition of ATI 718Plus ${ }^{\circledR}$ Starting Material

\begin{tabular}{|l|c|c|c|c|c|c|c|c|c|c|}
\hline Chemistry & $\mathrm{C}$ & $\mathrm{Cr}$ & $\mathrm{Mo}$ & $\mathrm{W}$ & $\mathrm{Co}$ & $\mathrm{Fe}$ & $\mathrm{Nb}$ & $\mathrm{Ti}$ & $\mathrm{Al}$ & $\mathrm{Ni}$ \\
\hline$\% \mathrm{w} / \mathrm{w}$ & 0.020 & 17.88 & 2.69 & 1.03 & 9.15 & 9.72 & 5.48 & 0.76 & 1.51 & $\mathrm{Bal}$. \\
\hline
\end{tabular}

Extracted segments were forged and rolled considering standard industrial parameters. Involved temperatures for hot-working operations were between $1200^{\circ} \mathrm{C}$ and $950^{\circ} \mathrm{C}$. Final deformation stages were performed near delta solvus to promote a fine grain size distribution. Contoured rings were cut and segments from these rings were exposed to heat treatment conditions listed in Table II. Some of such segments were ring slices used for grain size mapping after forging operations and after each heat treatment operation.

Table II: Heat Treatment Conditions for ATI 718Plus® Ring Segments.

\begin{tabular}{|c|c|l|}
\hline Condition & Solution heat treatment & Precipitation heat treatment \\
\hline HT1 & $954^{\circ} \mathrm{C} / 2 \mathrm{hr} /$ Air-cooling & $\begin{array}{l}788^{\circ} \mathrm{C} / 8 \mathrm{hr} / \text { furnace cooling to } 704^{\circ} \mathrm{C}+ \\
704^{\circ} \mathrm{C} / 8 \mathrm{hr} / \text { Air-cooling }\end{array}$ \\
\hline HT2 & $982^{\circ} \mathrm{C} / 2 \mathrm{hr} /$ Air-cooling & $\begin{array}{l}788^{\circ} \mathrm{C} / 8 \mathrm{hr} / \text { furnace cooling to } 704^{\circ} \mathrm{C}+ \\
704^{\circ} \mathrm{C} / 8 \mathrm{hr} / \text { Air-cooling }\end{array}$ \\
\hline HT3 & $1010^{\circ} \mathrm{C} / 2 \mathrm{hr} /$ Air-cooling & $\begin{array}{l}788^{\circ} \mathrm{C} / 8 \mathrm{hr} / \text { furnace cooling to } 704^{\circ} \mathrm{C}+ \\
704^{\circ} \mathrm{C} / 8 \mathrm{hr} / \text { Air-cooling }\end{array}$ \\
\hline
\end{tabular}

Samples from the "as forge" condition and from each heat treatment condition were evaluated by optical microscopy in order to determine grain size evolution. Characterization of samples, relative to the presence of delta-phase was evaluated by scanning electron microscopy.

Mechanical testing at elevated temperature, tensile and stress-rupture was performed on fully heattreated samples. Elevated tensile testing was performed at $704^{\circ} \mathrm{C}$. Stress-rupture testing was performed at $704^{\circ} \mathrm{C}$, initial load was $621 \mathrm{MPa}$; after 39.0 hours of testing incremental loading was conducted with increments of $34.5 \mathrm{MPa}$ at intervals of 8.0 hours.

\section{Results and discussion}

Evaluation of samples after hot-working operations, or "as forge" condition, revealed a uniform fully re-crystallized microstructure along the transversal section of each segment (despite their contoured shape). Figure 1 shows a representative segment of a contoured ring in the "as forge" condition. This result reveals ATI 718Plus ${ }^{\circledR}$ excellent forgeability characteristics and effect of recovery phenomenon during deformation at selected hot working temperature range. Consequence of the forging/rolling parameters considered for rings manufacture, reported average grain size is 44.9 micron (ASTM 6.0) to 63.5 micron (ASTM 4.0).

Since fully recrystallized microstructures were promoted during hot-working operations, a limited effect of Solution heat treatments was observed on rings segments: samples exposed to HT1 heat treatment presented an average grain size of 40.0 micron (ASTM 6.5). When rings segments are exposed to HT2 conditions, limited grain coarsening is promoted since reported average grain-size measurements are 50.0 micron (ASTM 5.5.). Samples exposed to HT3 parameters, developed grain coarsening, showing an average grain size of 60.0 micron (ASTM 5.0). Figure 2 present representative images of described microstructures. 


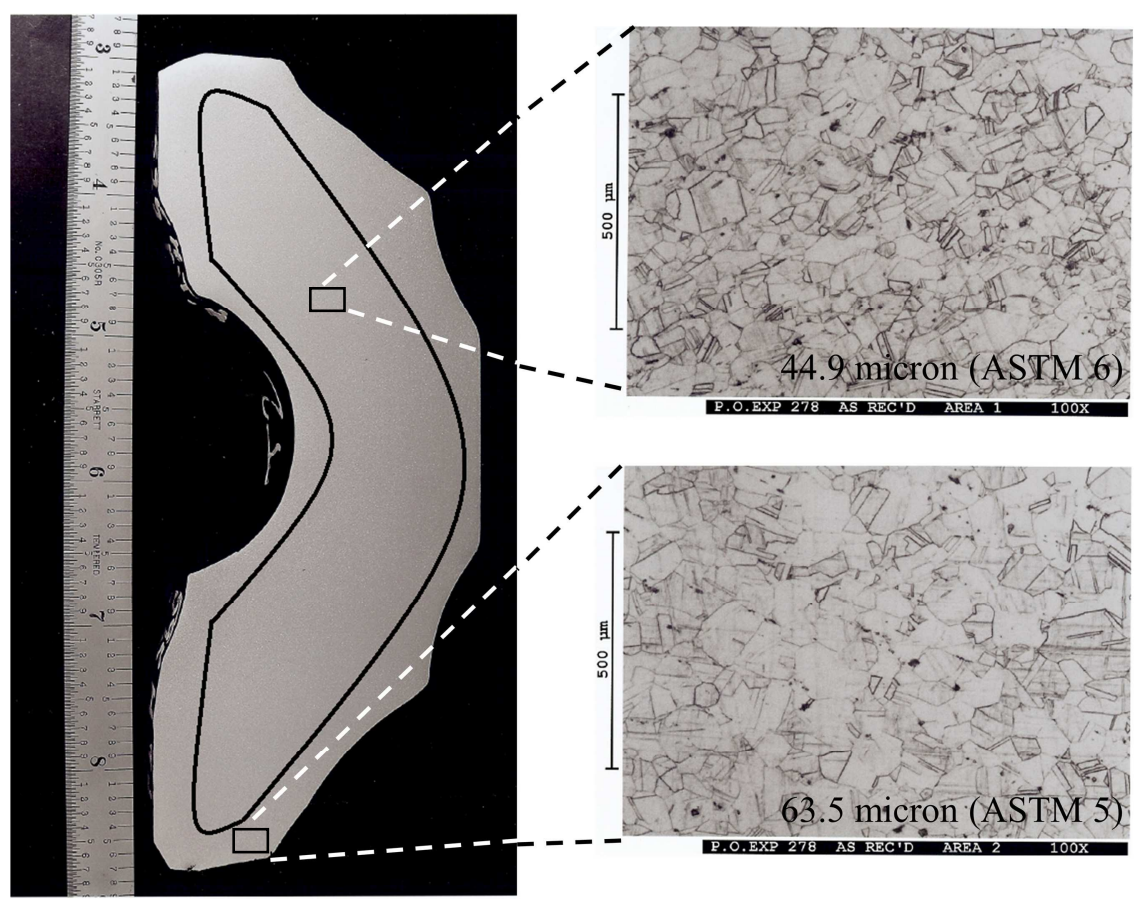

Figure 1: Representative microstructure of a ATI 718Plus ${ }^{\circledR}$ contoured ring in the "as forge" condition. A uniform fully recrystallized microstructure is observed.
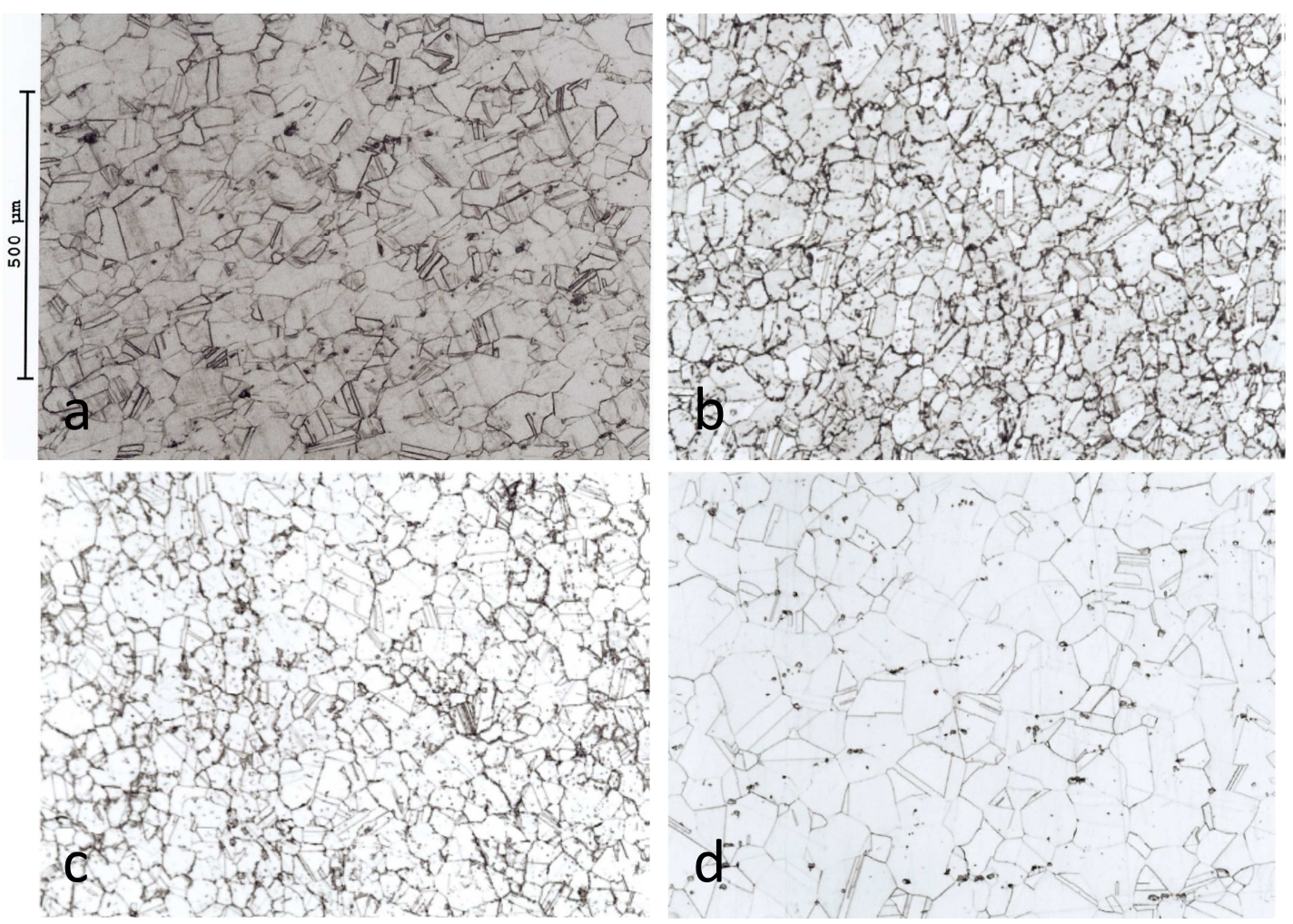

Figure 2: Effect of ring-rolling procedure and heat treatment processing on a ATI 718Plus ${ }^{\circledR}$ contoured ring. a) "as forge" condition, with a fully recrystallized microstructure. b) HT1 condition, showing a uniform average grain size of 40.0 micron. c) HT2 condition showing a uniform microstructure with average grain size of 50.0 micron. d) HT3 condition showing a coarsened average grain size of 60.0 micron as solution was performed near delta solvus. 

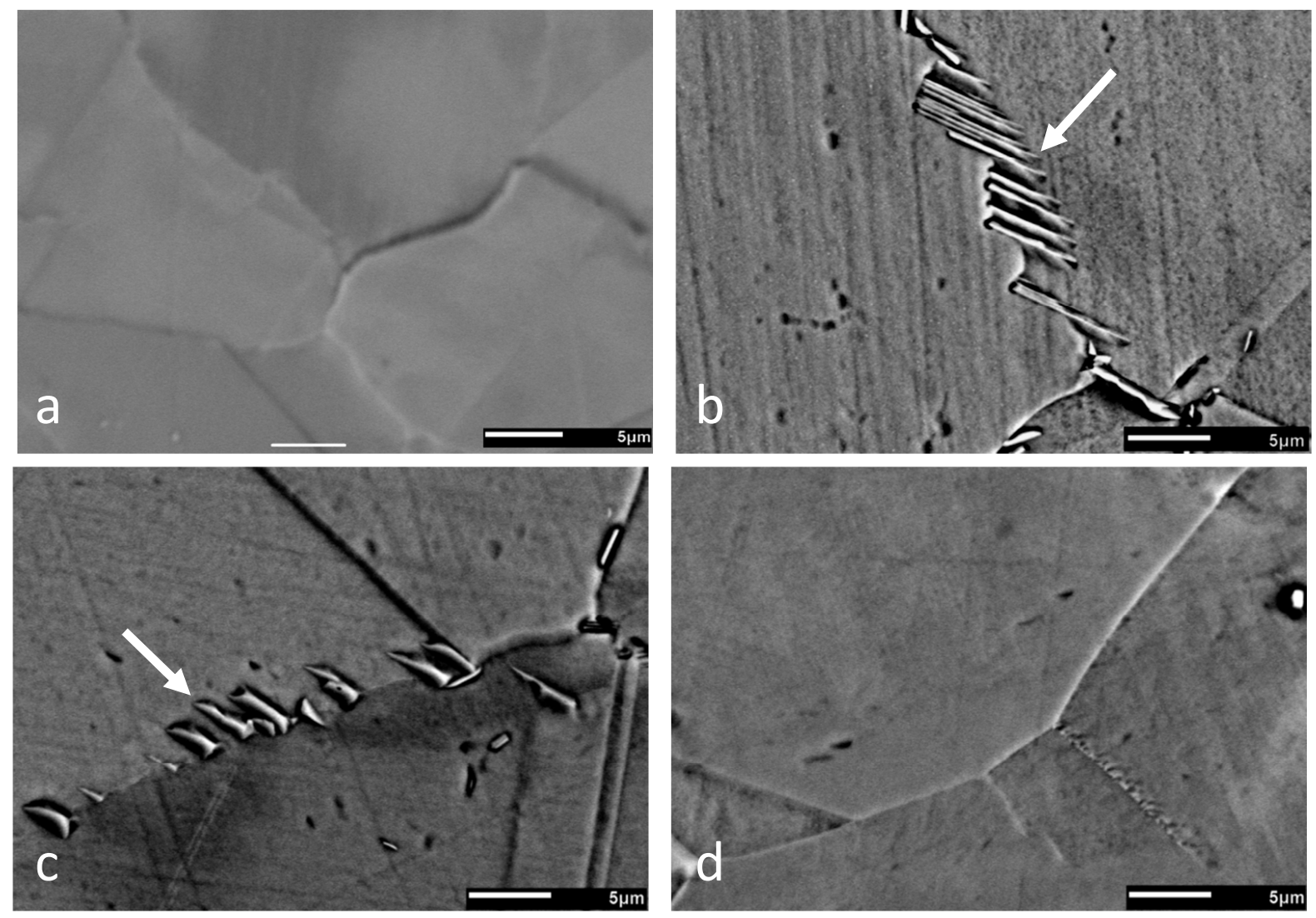

Figure 3: Representative microstructures of ATI 718Plus ${ }^{\circledR}$ alloy: a) "As forge" microstructure, no evident delta-phase is present at grain boundaries. b) Microstructure exposed to HT1 heat treatment, arrow indicates presence of delta-phase precipitates at grain boundary. c) Microstructure of 718Plus

alloy exposed to HT2 heat treatment, arrow indicates limited delta-phase precipitates at grain boundary. d) Microstructure of alloy exposed to HT3 heat treatment, no evident delta-phase precipitates at grain boundaries can be observed.

An important effect of solution heat treatment in superalloy ATI 718Plus ${ }^{\circledR}$ is the promotion of delta-phase at grain boundaries. A detailed evaluation of "as forge" samples and solutioned and precipitated samples reveals effect of heat treatment in this microstructural characteristic.

For the "as forge" samples, it was found a lack of evident delta phase at grain boundaries. This is a consequence of selected hot-working temperature range, which is near reported delta solvus temperature $[5,7]$. For the samples that were exposed to solution and precipitation heat treatments, different concentrations of delta-phase at grain boundaries are observed. Samples exposed to HT1 heat treatment show and important presence of delta-phase at grain boundaries. Presence of deltaphase precipitates at grain boundaries is limited in samples exposed to HT2 conditions. Evaluation of grain boundaries of samples exposed to HT3 heat treatment procedures reveals absence of evident delta-phase. Figure 3 present representative images of described microstructures.

It must be considered that same precipitation procedures were performed for heat-treated rings segments, with variation in solution temperature according listed condition. It is observed that presence of delta-phase at grain boundaries is not consequence of precipitation procedures, since samples exposed to condition HT3 do not show this precipitate. Another negative effect of lack of delta-phase at grain boundaries is grain growth reported for samples exposed to condition HT3. For samples exposed to HT1 and HT2 conditions, presence of delta-phase at grain boundaries is evident, indicating effect of solution in ATI 718Plus ${ }^{\circledR}$ alloy: when this superalloy is exposed to solution at $954^{\circ} \mathrm{C}$, greater amount of delta-phase at grain boundaries is promoted. As solution temperature is increased, presence of this intergranular precipitate is inhibited, as evaluation of samples exposed to HT2 condition revealed during observation. 
Effect of solution and precipitation conditions involved in heat treatment procedures is reflected by 718Plus ${ }^{\circledR}$ behavior when tensile properties are evaluated at high temperature. It was observed a decrease on tensile properties as a function of heat treatment procedure: as samples were exposed to HT1, HT2 and HT3 conditions, lower tensile properties were developed by ATI 718Plus ${ }^{\circledR}$ superalloy.

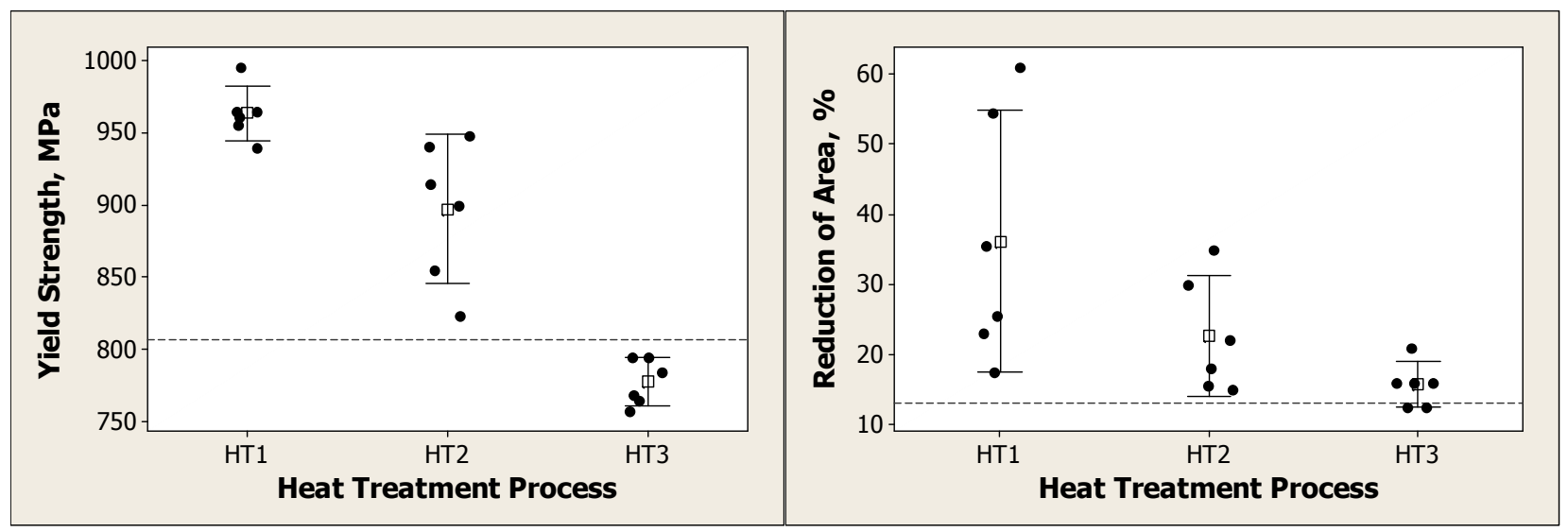

Figure 4: 718Plus ${ }^{\circledR}$ tensile properties at $704^{\circ} \mathrm{C}$ after solution and precipitation procedures.

Figure 4 presents observed tensile properties at elevated temperature testing. It can be seen that yield strength is affected as ATI 718Plus ${ }^{\circledR}$ alloy is exposed to heat treatment procedure. Samples exposed to condition HT1 developed consistently best yield strength; in the other side, lower values are observed for samples exposed to heat treatment HT3.

Observed reduction of area presents a similar behavior for rings segments, since higher values for this tensile property are reported for samples exposed to condition HT1. Reduction of area property at $704^{\circ} \mathrm{C}$ is reduced as rings segments are exposed to conditions HT2 and HT3.
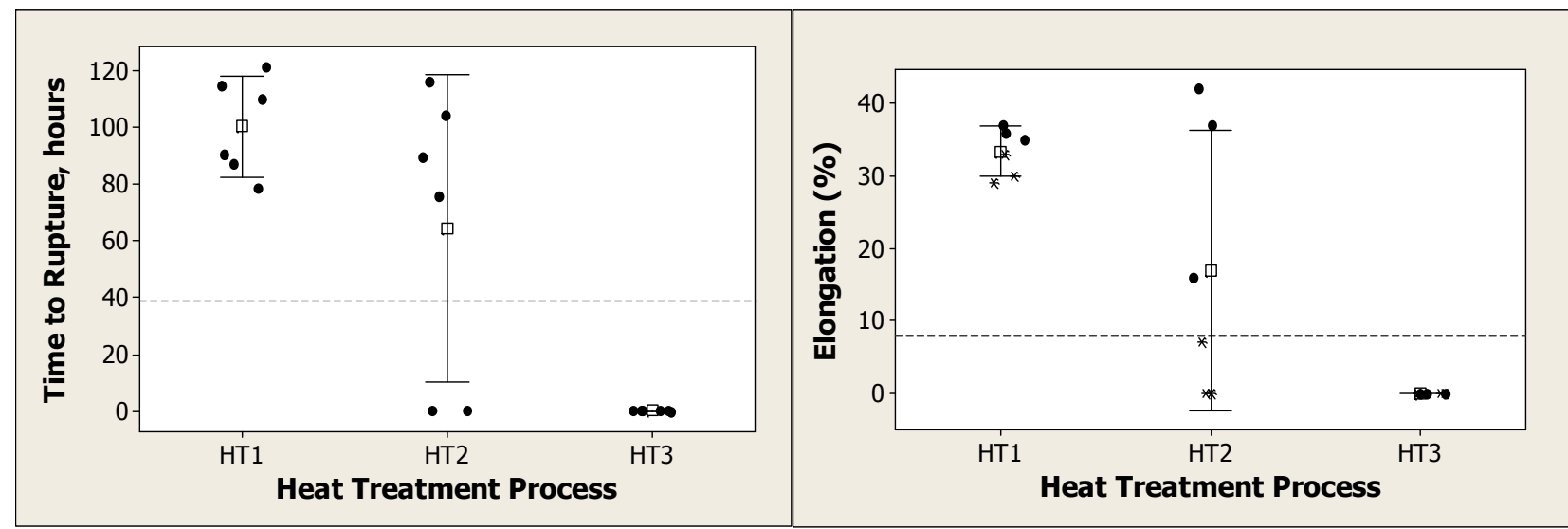

Figure 5: 718Plus ${ }^{\circledR}$ stress-rupture properties at $704^{\circ} \mathrm{C}$ and incremental loading after solution and precipitation procedures.

Effect on stress-rupture properties at $704^{\circ} \mathrm{C}$ is reported as Figure 5. It was observed that samples exposed to heat treatment HT1 presented best time to rupture and elongation values for considered testing conditions. As superalloy ATI 718 Plus ${ }^{\circledR}$ is exposed to condition HT2, where solution at $982^{\circ} \mathrm{C}$ promotes a limited amount of delta-phase at grain boundaries and limited grain coarsening is observed, alloy presents an inconsistently behavior, as failures were reported. Finally, all samples exposed to heat treatment HT3 failed stress-rupture testing. 
Relationship of described tensile and stress-rupture properties to microstructural characteristics can be as follows: similar grain size is observed for rings segments exposed to the three heat treatment procedures. Main difference between samples is presence and morphology of delta-phase at grain boundaries. Optimal microstructure to develop best tensile and stress-rupture properties at elevated temperature shall be a fine grain size (37.8 micron as average) and presence of delta phase at grain boundaries. These characteristics are well promoted when alloy is exposed considered hot-working condition and heat treatment HT1.

\section{Summary}

Based on presented results, it is possible to enounce next conclusions:

a) ATI 718Plus ${ }^{\circledR}$, alloy develops excellent forgeability characteristics for ring-rolling of contoured shapes.

b) Uniform fully recrystallized microstructures can be promoted in contoured rings with appropriate hot-working conditions near delta solvus temperature.

c) Optimal mechanical properties are promoted when 718 Plus ${ }^{\circledR}$ present an average grain size of 40.0 micron and presence of delta-phase at grain boundaries.

d) Fine grain size and presence of delta-phase at grain boundaries can be promoted with adequate forging/rolling procedures and a heat treatment process which include a solution operation at $954^{\circ} \mathrm{C}$.

\section{Acknowledgements}

Frisa Aerospace SA de CV recognize Conacyt support by INNOVAPYME project 110988 and contribution of ATI Allvac for the realization of this manuscript.

\section{References}

1. ATI 718 Plus ${ }^{\circledR}$ Alloy Data Sourcebook, Version 1.1, Allegheny Technologies Company, 2010, USA.

2. R.A. Jeniski, ATI Allvac, personal communication, 2010, Mexico.

3. E.A. Ott, J. Groh \& H. Sizek, Metals Affordability Initiative: Application of Allvac Alloy 718Plus ${ }^{\circledR}$ for Aircraft engine Static Structural Components, Superalloys 718, 625, 706 and Derivatives 2005, The Minerals, Metals \& Materials Society, 2005, USA.

4. ASM Handbook V.14 Forming and Forging, ASM International, 1996, USA.

5. X. Xie, C. Xu, G. Wang, J. Dong, W.D. Cao \& R. Kennedy, TTT Diagram of a Newly Developed Nickel-Base Superalloy- Allvac ${ }^{\circledR}$ 718Plus ${ }^{\circledR}$, Superalloys 718, 625, 706 and Derivatives 2005, The Minerals, Metals \& Materials Society, 2005, USA.

6. R.A. Jeniski \& R.L. Kennedy, Development of ATI Allvac ${ }^{\circledR} 718$ Plus ${ }^{\circledR}$ Alloy and Applications 718, 625, 706 and Derivatives 2005, The Minerals, Metals \& Materials Society, 2005, USA.

7. W.D. Cao \& R.L. Kennedy, Recommendations for Heat Treating Allvac ${ }^{\circledR} 718$ Plus ${ }^{\circledR}$ Alloy Parts, ATI Allvac Research \& Development, 2006, USA. 